\title{
A Rare Manifestation of Signet Ring Cell Carcinoma Stomach as Cutaneous Metastatic Deposits
}

\author{
Dr. Nitesh Kumari ${ }^{1}$, Dr. Sonu Kalyan ${ }^{2 *}$
}

${ }^{1}$ Pathologist, Tapadia diagnostic centre, Hyderabad, India

${ }^{2}$ Former Resident, Department of pathology, KCGMC, Karnal, Haryana, India

DOI: $\underline{10.36347 / \text { sjmcr.2020.v08i05.005 }}$

| Received: 25.04.2020 | Accepted: 03.05.2020 | Published: 12.05.2020

*Corresponding author: Dr. Sonu Kalyan

Abstract

Case Report

Cutaneous metastasis from visceral tumors is a rare entity with a reported incidence between $0.3 \%$ and $9.8 \%$. Cutaneous metastasis of gastric adenocarcinoma is also rare and usually presents in men, as nodules over the abdomen. We present a case of 35 year old man who is a known case of primary diffuse infiltrating signet ring cell carcinoma stomach presenting with surprising clinicopathological manifestation as cutaneous and intermuscular plane metastatic deposits on arm, forearm and lower abdomen. FNAC was done from all the swellings and show metastasis deposits of adenocarcinoma which were PAS stain positive. Although such sites for metastatic deposits of signet cell carcinoma stomach is very rare but molecular genetics and hematological spreads treasure us with its unexpected outcomes. So, clinician as well as pathologist must aware to manage these advanced end stage tumor manifestation as early as possible.

Keywords: Metastasis, cutaneous, carcinoma stomach.

Copyright @ 2020: This is an open-access article distributed under the terms of the Creative Commons Attribution license which permits unrestricted use, distribution, and reproduction in any medium for non-commercial use (NonCommercial, or CC-BY-NC) provided the original author and source are credited.

\section{INTRODUCTION}

Cutaneous metastasis from visceral tumour is a rare entity with a reported incidence between $0.3 \%$ and $9.8 \%$. Lesions have, however, been reported to appear on the head and neck area, axilla, chest, and the fingertip. Cutaneous metastasis of gastric adenocarcinoma is also rare and usually presents in men, as nodules over the abdomen [1].

\section{CASE Report}

We report a case of a 35year old man presented to the fine needle aspiration (FNA) clinic with chief complaints of body-ache, loss of appetite and multiple cutaneous swellings. He was a known case of diffuse infiltrating signet ring cell carcinoma of stomach and therapeutic partial gastrectomy was done. After partial gastrectomy patient was started on chemotherapy and despite of being on chemotherapeutic drugs from last few months, his cutaneous nodular swellings are increasing in size. A simultaneous computed tomography scan showed disease progression. The swellings were present on the right arm, forearm and abdomen each measuring $7 \times 5$ $\mathrm{cm}, 5 \times 4 \mathrm{~cm}$ and $4 \times 3 \mathrm{~cm}$ respectively[2]. The swellings over right arm (Figure 1) and forearm were slow growing, diffuse, non-ulcerated, firm in consistency and ill-defined margins with intermuscular plane location. The abdominal swelling presented as ulcerated painful multi-nodular growth with erythema of surrounding skin (Figure 2). Clinically it was suspected as metastatic deposits from carcinoma stomach as it was a known case of diffuse infiltrating signet ring cell carcinoma of stomach. FNAC was performed from all the swellings and yielded blood mixed aspirate. FNAC smears examined were cellular and showed loose cohesive groups, clusters as well as singly scattered Tumor cells (Figure 3\&4). Tumor cells showed moderate pleomorphism, round to ovoid nuclei, prominent nucleoli in some of them with moderate amount of cytoplasm. Some of the tumor cells showed signet ring cell morphology with cytoplasmic mucin pushing the nuclei to the periphery, which was highlighted by PAS staining (Figure5). So the final diagnosis made on FNAC was cutaneous metastatic deposits of carcinoma stomach which was quite a surprising manifestation of carcinoma stomach with very few reports found in the literature[3]. 


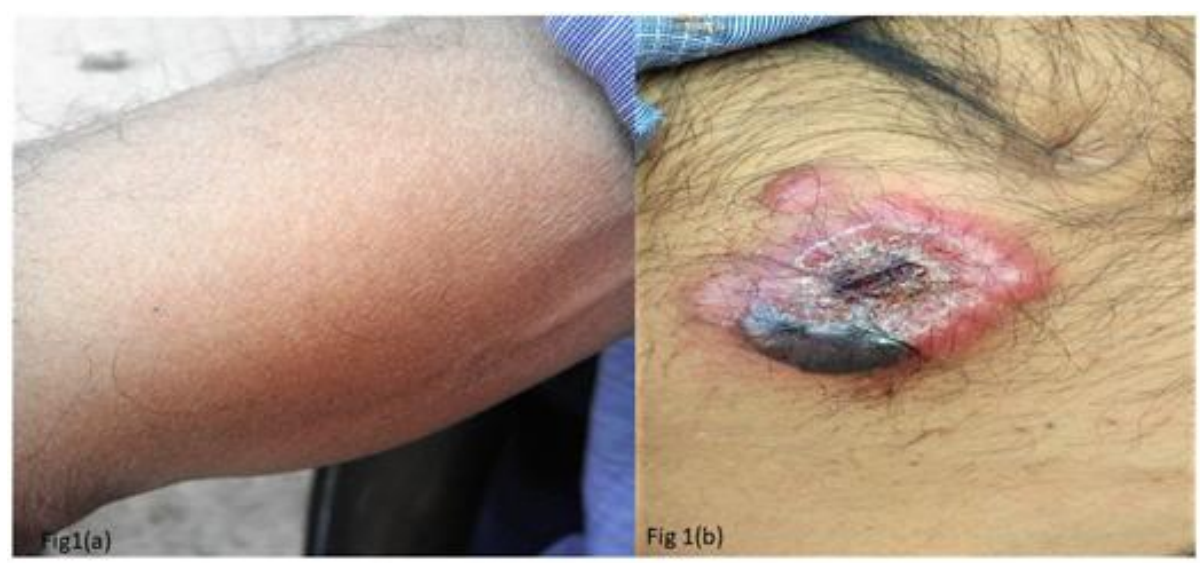

Fig-1(a\&b): Swelling over right arm and Ulcerated painful erythematous nodule over abdomen near umbilicus.

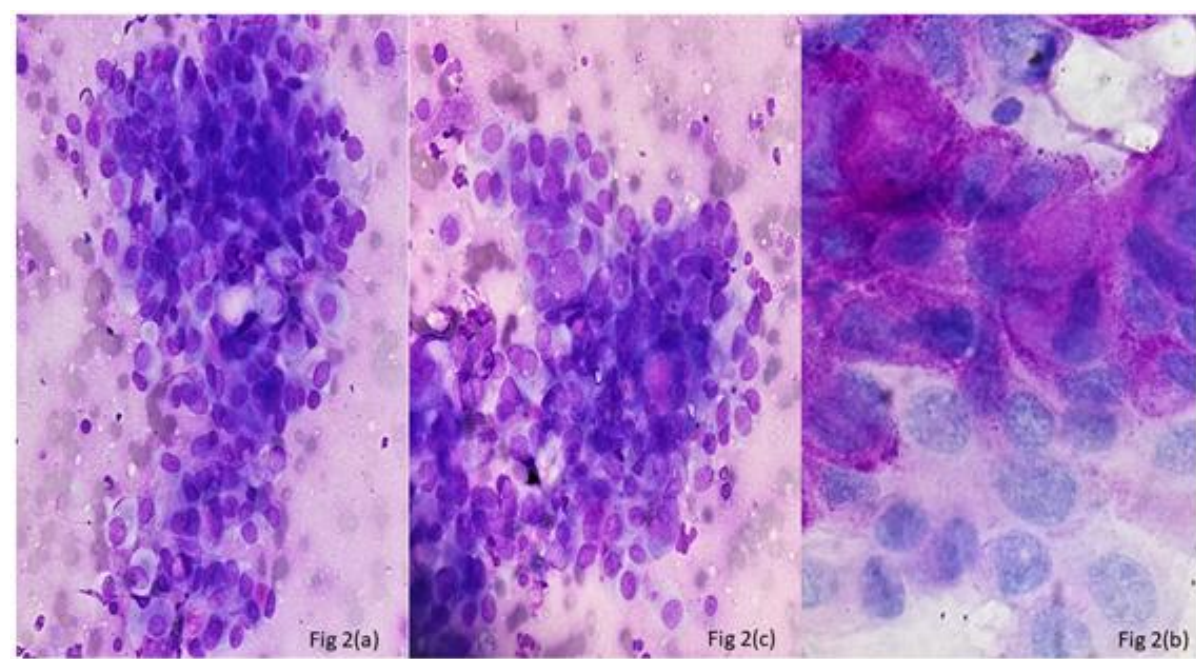

Fig-2 (a), (b) \& (c): Fine needle aspiration from arm swelling shows loosely cohesive clusters and moderately scattered pleomorphic tumor cells $(2 a \& b$ Leishman stain, $\times 400)$ and fine needle aspiration smear with PAS staining showing PAS positivity in the cytoplasm of tumour cells at 400x

\section{DISCUSSION}

Cutaneous metastasis from visceral tumors is a rare entity with a reported incidence between $0.3 \%$ and $9.8 \%$. Cutaneous metastases of visceral malignancies usually occur late in the course of the disease, the average time interval between the diagnosis of malignancy and presentation of cutaneous metastases has been reported to be 33 months. The clinical presentation of cutaneous metastases of visceral malignancies was classified by Brownstein and Helwig into nodular, inflammatory, fibrotic, and sclerodermoid types. The other lesions that have been described in literature include indurated or infiltrated nodules, indurated plaques, papulosquamous lesions, bullae, ulcers, erysipelas-like erythema (carcinoma erysipeloides), large indurated plaques resembling a coat of armor (carcinoma en cuirasse), scarring alopecia (alopecia neoplastica), and zosteriform pattern of metastases[4,5].

The typical site of location of metastatic lesions from the gastrointestinal tract is on the anterior abdominal wall. Palpable, nodular lesions bulging into the umbilicus have been called "Sister Mary Joseph" nodules. Lesions have, however, been reported to appear on the head and neck area, axilla, chest, and the finger tip. We present a known primary case diffuse infiltrating signet ring cell type carcinoma stomach that had multiple lesions involving the arm, forearm and lower abdomen, which may be due to hematogenous spread of the tumour. The presence of cutaneous metastases indicates an advanced stage of the malignancy $[6,7]$.

Cutaneous lesions are usually correctly identified as metastases by the clinician before the pathologic diagnosis if the patient has a known past history of neoplasia; however, these lesions may be misdiagnosed as benign lesions, such as epidermal cysts, pyogenic granulomas, hemangiomas, herpes zoster or neurofibromas. So an early pathological diagnosis definitely helps in the timely management of such cases $[8,9]$.

\section{CONCLUSION}

Cutaneous metastasis from visceral tumours is quite rare and may have variable clinical presentations. It may have a clinical presentation that mimics other 
benign cutaneous disorders so; detailed clinical history and early pathological examination of such lesions have an important role in the management.

\section{REFERENCES}

1. Mueller TJ, Wu H, Greenberg RE, Hudes G, Topham N, Lessin SR. Cutaneous metastases from genitourinary 2004;63:1021-6.

2. Saeed S, Keehn CA, Morgan MB. Cutaneous metastasis: A clinical, pathological, and immunohistochemical appraisal. J Cutan Pathol. 2004;31:419-30.

3. Brownstein MH, Helwig EB. Patterns of cutaneous metastasis. Arch Dermatol. 1972;105:862-8.

4. Lifshitz OH, Berlin JM, Taylor JS, Bergfeld WF. Metastatic gastric adenocarcinoma presenting as an enlarging plaque on the scalp. Cutis. 2005;76:1946.

5. Aneiros-Fernandez J, Husein-ElAhmed H, AriasSantiago S, Escobar Gómez-Villalva F, Nicolae A,
O'Valle Ravassa F. Cutaneous metastasis as first clinical manifestation of signet ring cell gastric carcinoma. Dermatol Online J. 2010;16:9.

6. Nashan D, Müller ML, Braun-Falco M, Reichenberger S, Szeimies RM, BrucknerTuderman L. Cutaneous metastases of visceral tumours: A review. J Cancer Res Clin Oncol. 2009;135:1-14.

7. Lookingbill DP, Spangler N, Helm KF. Cutaneous metastases in patients with metastatic carcinoma: A retrospective study of 4020 patients. J Am Acad Dermatol. 1993;29:228-36.

8. Hori $M$ and Yoshida H. Statistical study of metastatic skin cancer-interrelation of the origin of primary tumor, metastatic skin lesions, prognosis and histopathology. Gan to Kagaku Ryoho. 1998;15:1576-80.

9. Kikuchi Y, Matsuyama A and Nomura K. Zosteriform metastatic skin cancer: report of three cases and review of the literature. Dermatology. 2001;202: 336-8. 